\title{
A Biliary Recurrence of a Breast Cancer: Case Report and Review of the Literature
}

\author{
Fatima Zahra El M'rabet1, Hanae Bedoudou1*, Adil Mai'2, Amina Arramdani33, Boubacar Efared4, \\ Laila Chbani $^{4}$, Ihssane Mellouki ${ }^{3}$, Dafr Allah Benajah ${ }^{3}$, Youssef Alaoui Lamrani' ${ }^{2}$, Nawfel Mellas ${ }^{1}$ \\ ${ }^{1}$ Oncology Department, University Hospital Hassan II, Fez, Morocco \\ ${ }^{2}$ Radiology Department, University Hospital Hassan II, Fez, Morocco \\ ${ }^{3}$ Hepatogastroenterology Department, University Hospital Hassan II, Fez, Morocco \\ ${ }^{4}$ Anatomical Pathology and Cytology Laboratory, University Hospital Hassan II, Fez, Morocco \\ Email: *hanae.bedoudou@usmba.ac.ma
}

How to cite this paper: El M'rabet, F.Z., Bedoudou, H., Mai, A., Arramdani, A., Efared, B., Chbani, L., Mellouki, I., Benajah, D.A., Lamrani, Y.A. and Mellas, N. (2017) A Biliary Recurrence of a Breast Cancer: Case Report and Review of the Literature. Journal of Cancer Therapy, 8, 296-301. https://doi.org/10.4236/jct.2017.83025

Received: January 10, 2017

Accepted: March 28, 2017

Published: March 31, 2017

Copyright $\odot 2017$ by authors and Scientific Research Publishing Inc. This work is licensed under the Creative Commons Attribution International License (CC BY 4.0).

http://creativecommons.org/licenses/by/4.0/

\begin{abstract}
A 51-year-old female with a history of radical mastectomy with axillary lymph node dissection, adjuvant chemotherapy and radiation for a breast cancer was referred to the emergency room due to cholangitis. A CT scan showed a common bile duct mass invading the duodenum. After bile draining, the investigations led to an undifferentiated carcinoma with positive hormonal receptors. The diagnosis of a breast cancer recurrence was established and the patient was commenced on taxane therapy.
\end{abstract}

\section{Keywords}

Breast Cancer, Recurrence, Cholangitis, Biliary Tumor, Metastasis, Hormonal Receptors, Chemotherapy

\section{Introduction}

Breast cancer is the most frequently diagnosed cancer globally. It's the leading cause of death by cancer in women. The systemic treatment of breast cancer recurrence prolongs survival and enhances quality of life but is not curative. Therefore, treatment associated with minimal toxicity should be preferred.

Extrahepatic biliary obstruction caused by metastatic breast carcinoma is rare. In most reported cases, biliary obstruction was related to metastatic periductal or peripancreatic lymph nodes [1]-[9]. The management of these cases relies on systemic therapy and local palliative interventions.

\section{Case Study}

In November 2015, a 51-year-old female was referred to the emergency room in 
our institution due to cholangitis. Laboratory tests showed increased total and conjugated hyperbilirubinemia ( $52 \mathrm{mg} / \mathrm{dl}$ and $43 \mathrm{mg} / \mathrm{dl}$, respectively). A CT scan showed a common bile duct tumor invading the duodenum (Figure 1), in addition to spread nodules in the lungs.

A duodenal prosthesis was introduced via an endoscopic retrograde cholangiopancreatography (ERCP) (Figure 2) but the procedure failed to catheterize the bile duct. An external draining of the bile was performed and biological parameters started to improve. Tumor markers, cancer antigen 19-9 (CA 19-9) and cancer antigen 125 (CA 125) were high (121.3 ui/ml and $123.5 \mathrm{ui} / \mathrm{ml}$ ). The histological analysis of a CT guided biopsy revealed that the tumor was an undifferentiated carcinoma (Figure 3).

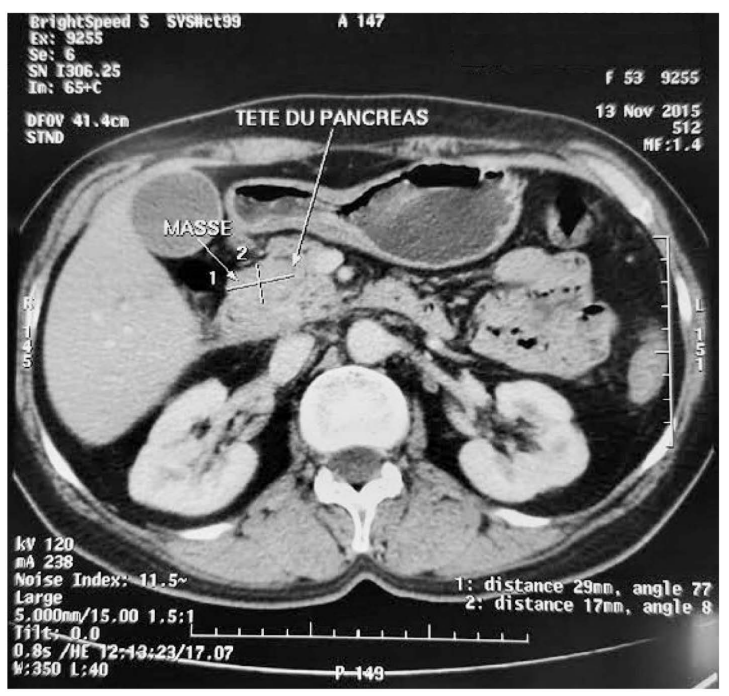

(a)

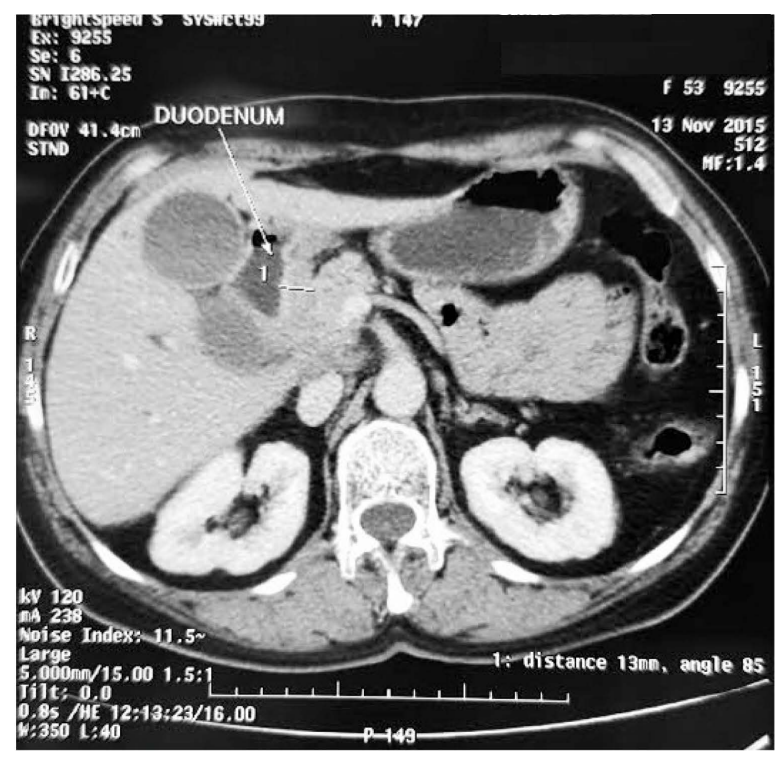

(b)

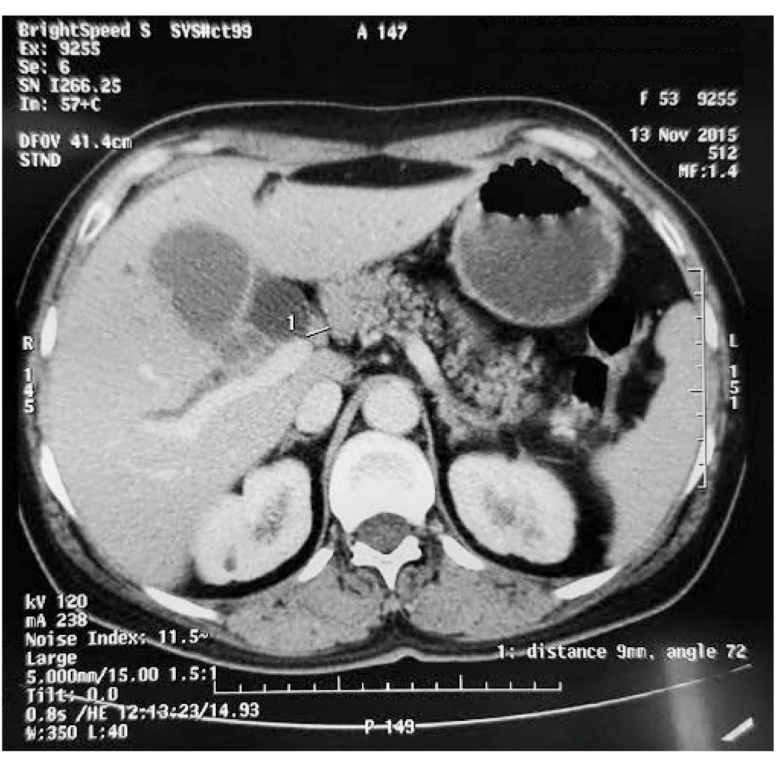

(c)

Figure 1. CT images of a common bile duct tumor invading the duodenum. (a) Mass centered on the lower part of the common bile duct, independent from the pancreas; (b) Tumoral thickening of the duodenal wall reflecting an invasion of the latter; (c) Dilation of the common bile duct (arrow head). The pancreatic duct is not dilated which confirms the tumor localization. 


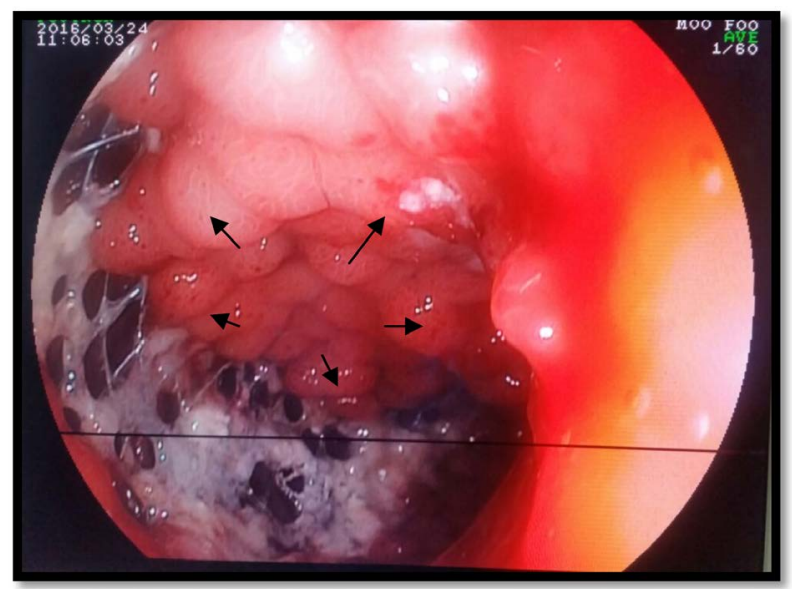

Figure 2. Endoscopic image of an exophytic tumor of the duodenum (arrows).

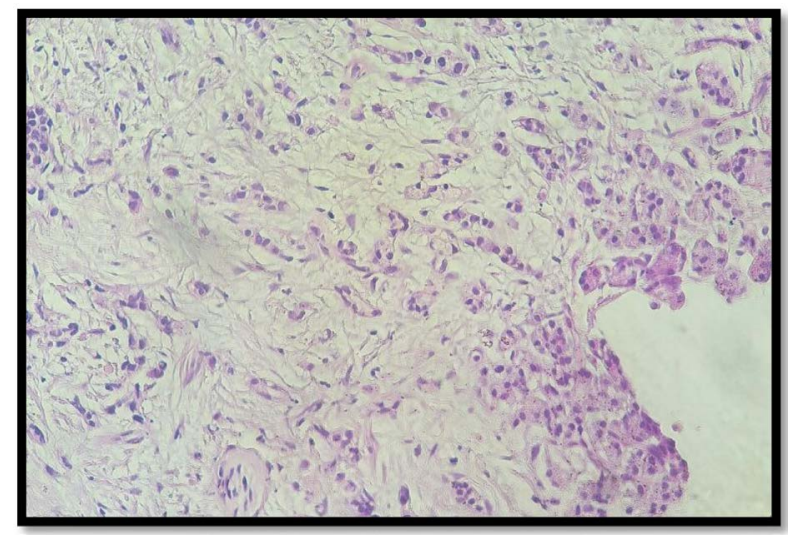

Figure 3. Tumor proliferation arranged in tubules (Hematoxylin-eosin-saffron $\times 20$ ).

In the patient's past medical history, 12 years earlier, the patient underwent a radical mastectomy with axillary lymph node dissection for a breast cancer. At that time there was no evidence of a distant metastasis. Histological analysis of the primary tumor revealed a $7 \times 4 \times 1 \mathrm{~cm}$ invasive ductal SBR Grade 2 carcinoma. The nipple, the surgical borders and all of the 12 lymph nodes removed were free from malignancy. Essays for hormonal receptors were weakly positive, with negative estrogen receptors and progesterone receptors at 30\%; human epidermal growth factor receptor 2 (HER2) and Ki-67 tests were not performed. After the mastectomy, the patient received adjuvant chemotherapy based on six cycles of AC 60 regimen (cyclophosphamide $600 \mathrm{mg} / \mathrm{m}^{2}$, doxorubicin $60 \mathrm{mg} / \mathrm{m}^{2}$ intravenously every three weeks), in addition to a subsequent radiation treatment and adjuvant hormonal therapy for the following five years based on a selective estrogen antagonist (Tamoxifen). Regular oncological follow-up were instituted and no recurrence had been detected throughout the years.

As the presumed diagnosis was that of a primary bile duct tumor, the case was discussed in the local cancer multidisciplinary meeting, the oncologists suggested a breast recurrence and breast hormonal receptors were looked for by immunostaining. Luckily for the patient, hormonal receptors were positive (Figure 4) and she received a taxane first line chemotherapy (docetaxel $100 \mathrm{mg} / \mathrm{m}^{2}$ every 3 weeks 


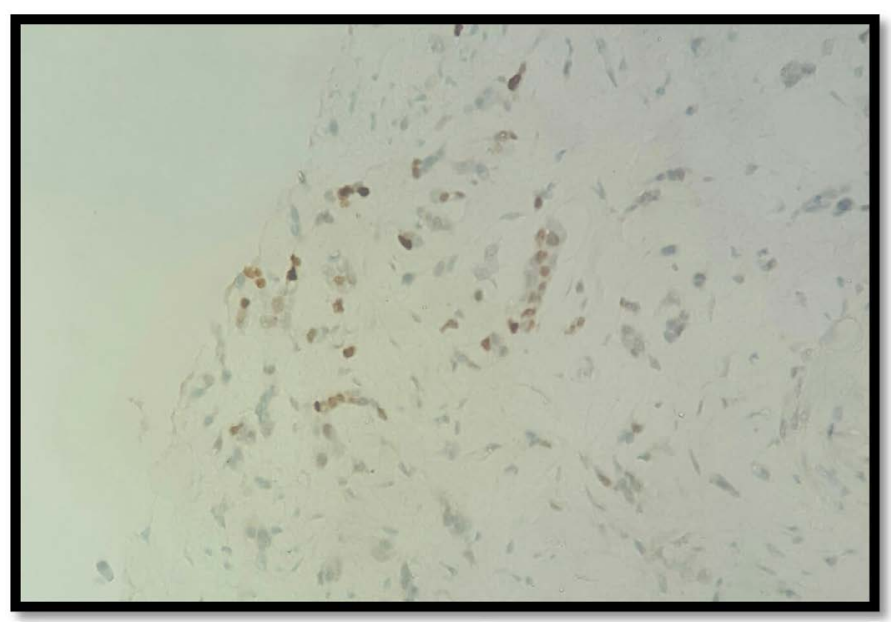

Figure 4. Expression of estrogen receptors (Immunostaining $\times 20$ ).

intravenously) after normalization of laboratory tests. The chemotherapy induced an increase in hepatic biological parameters, we first reduced the docetaxel dose by $25 \%$, after 3 months she had a stable disease. The patient continued to worsen her cholestasis. A duodenal prosthesis was inserted via ERCP and the procedure was successful this time. We decided to start exclusive palliative care due to biological contraindication and PS deterioration. The patient died shortly after.

\section{Discussion}

Extrahepatic biliary obstruction caused by metastatic breast carcinoma is rare. In most reported cases, biliary obstruction was related to metastatic periductal or peripancreaticlymph nodes [1]-[9]. Franco D. et al. [10] reported two cases of metastases of the proximal bile duct in women whose breast cancer had been diagnosed six and eight years earlier. In the first of these cases the tumor was mainly located in the lymphatic ducts within the bile duct wall while in the other it was transmural [10].

Pappo et al. [11] reported a case of an obstructive jaundice developed in a patient concomitantly with the diagnosis of breast carcinoma. After a vigorous surgical diagnostic approach, pathological examination demonstrated metastatic lobular carcinoma of breast in the head of the pancreas, the distal bile duct, and the gallbladder with strongly positive staining for estradiol. Additional hormonal therapy has been given to the patient since the operation. The patient was still alive 16 months after the diagnosis of her disease.

Papo M. et al. [12] reported a case of obstructive jaundice due to extrahepatic intraductal biliary metastasis from a breast carcinoma; the patient was treated by surgical decompression with relief of jaundice but died 5 months later.

Titus et al. [13] reported the case of an obstructive jaundice due to a metastatic breast cancer in the ampulla and distal common bile duct. A pancreaticoduodenectomie was performed.

Coletta et al. reported that a 56-year-old woman who had undergone a right 
mastectomy 13 years earlier due to infiltrating ductal breast cancer and had remained tumor free, presented at a follow-up examination with obstructive jaundice.

Imaging (computed tomography, magnetic resonance and endoscopic retrograde cholangiopancreatography) scans showed features that were suggestive of a primary tumor of the extrahepatic bile duct. At surgery, the intraoperative findings were also those of a tumor of the bile duct, however, an histological examination showed no evidence of malignancy in the mucosa, but did shown an infiltration of the external wall from adenocarcinoma. Immunohistochemistry analysis demonstrated that the tumor was metastatic breast cancer [14].

In almost all the cases, the surgery was the best option to palliate the symptoms however the diagnosis was never suspected before aggressive treatment. Rego et al. reported two cases where the bile duct was involved in the periampullary area and the endoscopic biopsy allowed a preoperative diagnosis [15].

In our case, the surgery was impossible and the diagnosis was based on clinical arguments (history of breast cancer) and immunostaining (hormonal receptors).

As for the endoscopic approach, large meta-analysis reviewing 2436 patients comparing surgical bypass, endoscopic metal stents, and endoscopic plastic stents concluded that endoscopic metal stents are the treatment of choice in patients with unresectable distal malignant biliary obstruction [16]. In this study, the percentage of the patient having metastatic disease of breast cancer wasn't mentioned.

\section{Conclusion}

Metastases from breast cancer can cause biliary complications in the absence of liver involvement, thus making the preoperative diagnosis is particularly difficult. Biliary metastasis should be considered in the differential diagnosis of obstructive jaundice due to the bile duct stenosis in patients with a history of breast cancer. The aggressive surgical treatment can be the best option especially if it's a unique metastatic localization, otherwise, endoscopic draining can give a good balance of risk benefit in this palliative strategy.

\section{References}

[1] Abrams, H.L., Spiro, R. and Goldstein, N. (1950) Metastases in Carcinoma. Analysis of 1000 Autopsied Cases. Cancer, 3, 74-85. https://doi.org/10.1002/1097-0142(1950)3:1<74::AID-CNCR2820030111>3.0.CO;27

[2] Dodd, G.D. (1967) Percutaneous Transhepatic Cholangiography. The Surgical Clinics of North America, 47, 1095-1106.

[3] Taylor, K.J.W., Carpenter, D.A. and McCready, V.R. (1974) Ultrasound and Scintigraphy in the Differential Diagnosis of Obstructive Jaundice. Journal of Clinical UItrasound, 2, 105-116. https://doi.org/10.1002/jcu.1870020205

[4] Chang, S.F., Burrell, M.I., Brand, M.H. and Garsten, J.J. (1978) The Protean Gastrointestinal Manifestations of Metastatic Breast Carcinoma. Radiology, 126, 611-617. 
https://doi.org/10.1148/126.3.611

[5] Meyer, J.E., Messer, R.J. and Patel, V.C. (1978) Diagnosis and Treatment of Obstructive Jaundice Secondary to Liver Metastases. Cancer, 41, 773-775. https://doi.org/10.1002/1097-0142(197802)41:2<773::AID-CNCR2820410252>3.0.C O;2-Q

[6] Rabin, M.S. and Richter, I.A. (1979) Metastatic Breast Carcinoma Presenting as Obstructive Jaundice. South African Medical Journal, 55, 388-90.

[7] Popp Jr., J.W., Schapiro, R.H. and Warshaw, A.L. (1979) Extrahepatic Biliary Obstruction Caused by Metastatic Breast Carcinoma. Annals of Internal Medicine, 91, 568-571. https://doi.org/10.7326/0003-4819-91-4-568

[8] Kopelson, G., Chu, A.M., Doucette, J.A. and Gunderson, L.L. (1980) Extra-Hepatic Biliary Tract Metastases from Breast Cancer. International Journal of Radiation Oncology Biology Physics, 6, 497-504. https://doi.org/10.1016/0360-3016(80)90066-8

[9] Iwasaki, M., Furuse, J., Yoshino, M., Konishi, M., Kawano, N., Kinoshita, T. and Ryu, M. (1996) Percutaneous Transhepatic Biliary Drainage for the Treatment of Obstructive Jaundice Caused by Metastases from Nonbiliary and Nonpancreatic Cancers. Japanese Journal of Clinical Oncology, 26, 465-468.

https://doi.org/10.1093/oxfordjournals.jjco.a023265

[10] Franco, D., Martin, B., Smadja, C., Szekely, A.-M. and Rougier, P. (1987) Biliary Metastases of Breast Carcinoma. The Case for Resection. Cancer, 60, 96-99.

https://doi.org/10.1002/1097-0142(19870701)60:1<96::AID-CNCR2820600117>3.0. CO;2-S

[11] Pappo, I., Feigin, E., Uziely, B. and Amir, G. (1991) Biliary and Pancreatic Metastases of Breast Carcinoma: Is Surgical Palliation Indicated? Journal of Surgical Oncology, 46, 211-214. https://doi.org/10.1002/jso.2930460318

[12] Papo, M., Fernandez, J., Quer, J.C., Sirvent, J.J. and Richart, C. (1996) Metastatic Breast Carcinoma Presenting as Obstructive Jaundice. American Journal of Gastroenterology, 91, 2240-2241.

[13] Titus, A.S., Baron, T.H., Listinsky, C.M. and Vickers, S.M. (1997) Solitary Breast Metastasis to the Ampulla and Distal Common Bile Duct. The American Surgeon, 63, 512-515.

[14] Coletta, M., Montalti, R., Pistelli, M., Vincenzi, P., Mocchegiani, F. and Vivarelli, M. (2014) Metastatic Breast Cancer Mimicking a Hilar Cholangiocarcinoma: Case Report and Review of the Literature. World journal of surgical oncology, 12, 384. https://doi.org/10.1186/1477-7819-12-384

[15] Rego, R.F., Atiq, M., Velchala, N., Nevin, D., McElreath, D.P., McKnight, W.D. and Aduli, F. (2009) Ampullary Metastasis from Breast Cancer: An Unusual Finding. Endoscopy, 41, E278-E279. https://doi.org/10.1055/s-0029-1215071

[16] Moss, A.C., Morris, E., Leyden, J. and MacMathuna, P. (2007) Malignant Distal Biliary Obstruction: A Systematic Review and Meta-Analysis of Endoscopic and Surgical Bypass Results. Cancer Treatment Reviews, 33, 213-221.

https://doi.org/10.1016/j.ctrv.2006.10.006 
Submit or recommend next manuscript to SCIRP and we will provide best service for you:

Accepting pre-submission inquiries through Email, Facebook, LinkedIn, Twitter, etc. A wide selection of journals (inclusive of 9 subjects, more than 200 journals)

Providing 24-hour high-quality service

User-friendly online submission system

Fair and swift peer-review system

Efficient typesetting and proofreading procedure

Display of the result of downloads and visits, as well as the number of cited articles Maximum dissemination of your research work

Submit your manuscript at: http://papersubmission.scirp.org/

Or contact jet@scirp.org 